\title{
An audit of the investigation and management of adrenal incidentalomas
}

\section{McElwaine $\mathrm{FH}^{1}$, Ellis $\mathrm{PK}^{\mathbf{2}}$, Bell PM${ }^{1}$, Courtney $\mathrm{CH}^{\mathbf{1}}$, Hunter SJ1, Mullan K' ${ }^{1}$, McCance DR ${ }^{1}$}

\section{${ }^{1}$ Regional Centre for Endocrinology and Diabetes, Royal Victoria Hospital, Belfast 2Department of Radiology, Royal Victoria Hospital, Belfast}

\author{
Background \\ The incidental adrenal mass is a serendipitously \\ discovered adrenal lesion, $>1 \mathrm{~cm}$, on radiologic \\ examination done for reasons other than to investigate for \\ primary adrenal disease ${ }^{1}$

\section{Excludes:} \\ Imaging done where there is a high suspicion/known malignancy \\ Clinically evident adrenal disease missed due to insufficient clinical \\ examination \\ Prevalence of adrenal incidentaloma $1-10 \%^{2}$ \\ -2-5\% adrenocortical carcinoma \\ -5.3\% subclinical Cushing's syndrome \\ $.5 \%$ clinically silent phaeochromocytomas \\ $\cdot 1 \%$ primary aldosteronism
}

\section{Objective}

To establish whether adrenal incidentalomas are being investigated and followed up appropriately

\section{Aims}

To ascertain whether adrenal incidentalomas being investigated as per American Association of Clinical Endocrinologists guidelines ${ }^{3}$

- All should be investigated for excess cortisol

- All should be investigated for excess catecholamines

- All hypertensive patients should be investigated for primary hyperaldosteronism

- All $>4 \mathrm{~cm}$ should be considered for surgical resection after hormonal evaluation

Methods
-All computed tomography (CT) imaging reports containing the words
'adrenal' and 'adenoma' for the year 2010 reviewed
-Reports searched manually, imaging done for cancer screening
excluded, imaging done to assess known adrenal lesions excluded
-Clinical information obtained from NIECR (Northern Ireland Electronic
Care Record)/clinical notes
-Laboratory information from Belfast Link Labs

\section{Source of patients $(n=95)$}

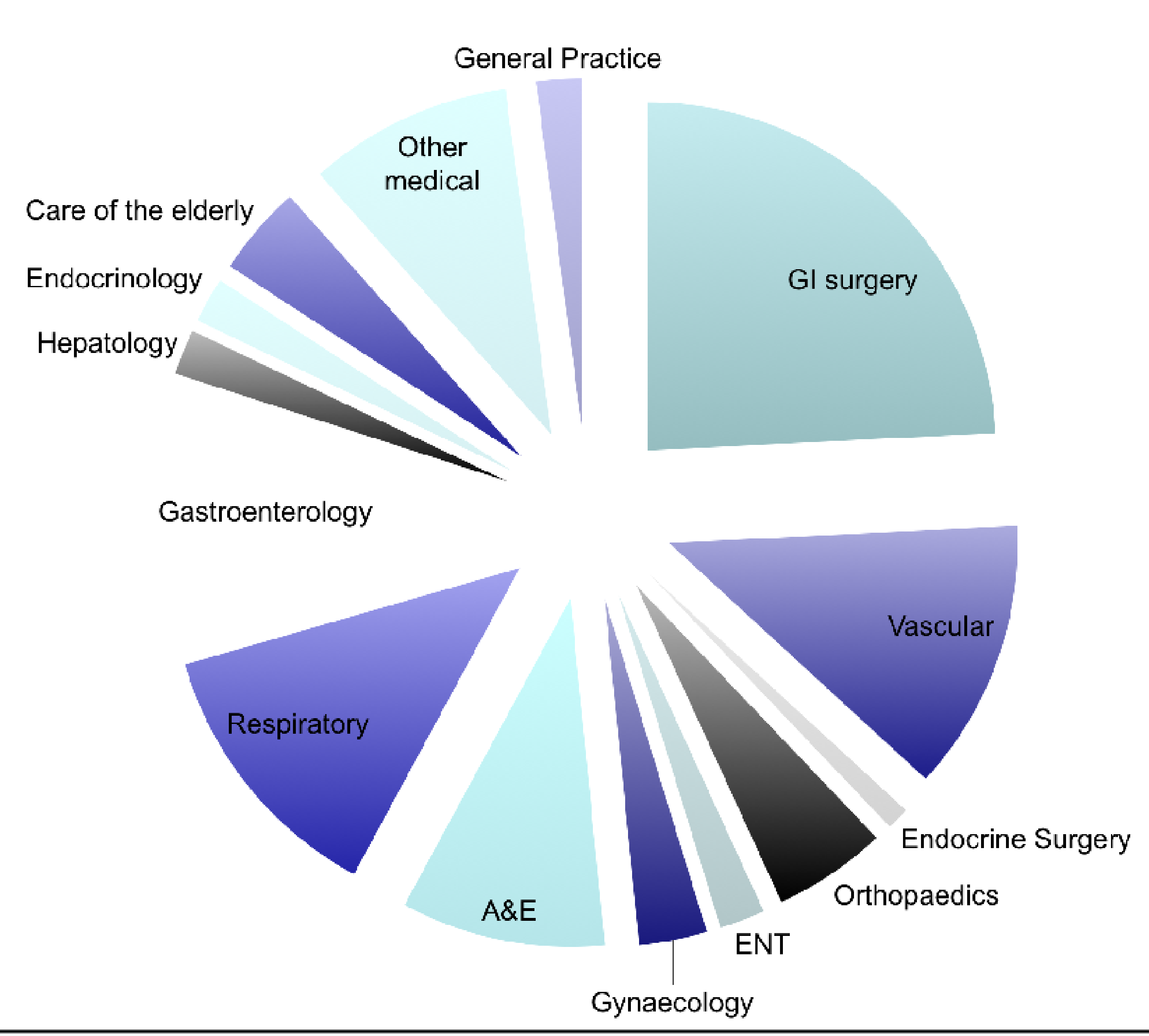

\section{Results}
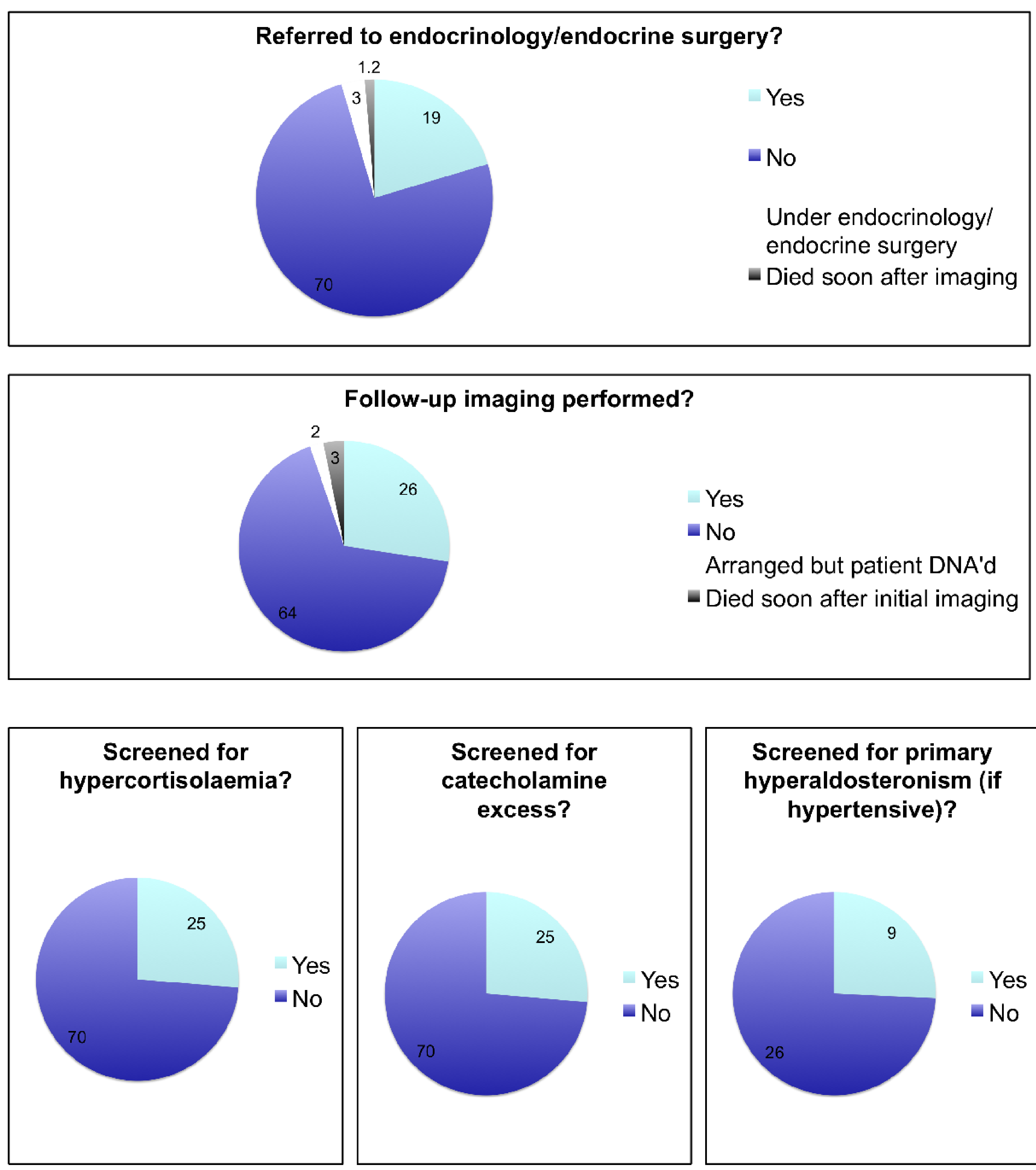

Screened for primary hyperaldosteronism (if hypertensive)?

\section{Summary}

-Adrenal incidentalomas frequently ignored by non endocrinologists

- If referred to endocrinology, all investigated appropriately

- If not referred to endocrinology, generally not investigated for hypersecretion

-Serious pathology may be being missed

\section{Recommendations \\ Radiology to highlight adrenal lesions $>1 \mathrm{~cm}$ in diameter on imaging reports \\ Radiology reports to advise endocrine referral for adrenal lesions $>1 \mathrm{~cm}$, if clinically appropriate (excluding myelolipomas)}

\begin{tabular}{|l|}
\hline References \\
1.NIH state-of-the-science statement on management of the clinically inapparent adrenal mass \\
("incidentaloma") NIH Consens State Sci Statements. 2002;19:1-25. \\
2. Young, WF. The Incidentally Discovered Adrenal Mass. NEJM. 2007; 356;6 \\
3.AACE/AAES Adrenal Incidentaloma guidelines, Endocr Pract. 2009;15(Suppl 1) \\
\end{tabular}

